\title{
Pragmatic nihilism: how a Theory of Nothing can help health psychology progress
}

\section{Gjalt-Jorn Ygram Peters \& Rik Crutzen}

To cite this article: Gjalt-Jorn Ygram Peters \& Rik Crutzen (2017): Pragmatic nihilism: how a Theory of Nothing can help health psychology progress, Health Psychology Review, DOI: 10.1080/17437199.2017.1284015

To link to this article: http://dx.doi.org/10.1080/17437199.2017.1284015

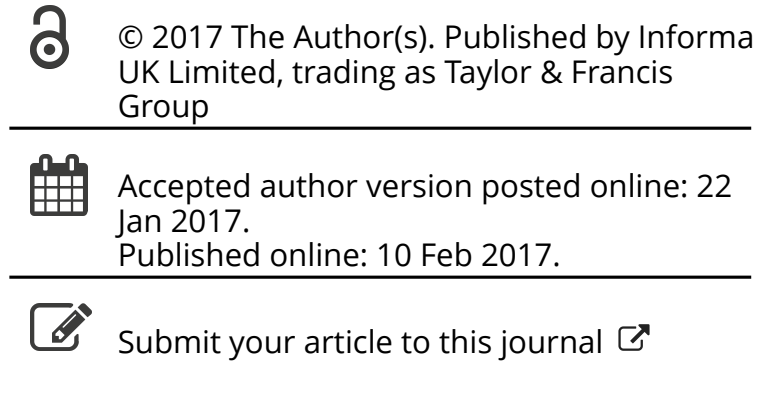

Џ Article views: 575

Q View related articles $\sqsubset$

View Crossmark data $\complement$ 


\title{
Pragmatic nihilism: how a Theory of Nothing can help health psychology progress
}

\author{
Gjalt-Jorn Ygram Peters ${ }^{\mathrm{a}, \mathrm{b}}$ and Rik Crutzen ${ }^{\mathrm{c}}$
}

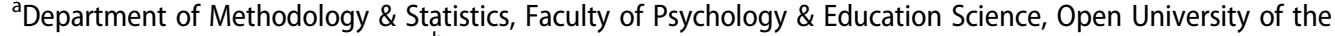
Netherlands, Heerlen, Netherlands; ${ }^{b}$ Faculty of Psychology \& Neuroscience, Department of Work \& Social Psychology, Maastricht University, Maastricht, Netherlands; 'Department of Health Promotion, Maastricht University/CAPHRI, Maastricht, Netherlands
\end{abstract}

\begin{abstract}
Health psychology developed a plethora of theories to explain and change a wide variety of behaviours. Several attempts have been undertaken to build integrative theories, some even striving for a Theory of Everything. We argue against these efforts, arguing that instead a 'pragmatic nihilism' perspective may be more fruitful to understand and change health behaviours. The first tenet of pragmatic nihilism is that psychological variables are usefully considered as metaphors rather than referring to entities that exist in the mind. As a consequence, the second tenet emphasizes theories' definitions and guidelines for the operationalisation of those variables. The third tenet of pragmatic nihilism is that each operationalisation represents an intersection of a variety of dimensions, such as behavioural specificity and duration, and most importantly, psychological aggregation level. Any operationalisation thus represents a number of choices regarding these dimensions. Pragmatic nihilism has two implications. First, it provides a foundation that enables integrating theories in a more flexible and accurate manner than made possible by integrative theories. Second, it emphasizes the importance of operationalisations, underlining the importance of investing in the careful development of measurement instruments, thorough reporting of measurement instruments' specifics and performance, and full disclosure of the instruments themselves.
\end{abstract}

\section{ARTICLE HISTORY}

Received 9 June 2016

Accepted 16 January 2017

\section{KEYWORDS}

Theory; operationalisation; integrative theory;

application

There have been many efforts to integrate health psychology theory (Hagger, 2009), such as the integration of self-determination theory (SDT) and the Theory of Planned Behaviour (TPB; Hagger \& Chatzisarantis, 2014), the multi-theory integration in the iChange model (de Vries et al., 2003), and the ambitions recently presented by Michie (2015). Given the plethora and continuous proliferation of health psychology theories, these efforts are understandable, for example to facilitate adoption of an approach to intervention development that 'cover[s] the full range of possible influences [and so does not] exclude potentially important variables' (Michie, van Stralen, \& West, 2011). Although valiant efforts in their own right, they have recently been criticised (Abraham, 2016; Albarracin \& Glasman, 2016; Johnston, 2016; Kok \& Peters, 2016; Ogden, 2016a, 2016b; Teixeira, 2016). We agree with those criticisms, but acknowledge that that leaves health psychology in a position where the theoretical wilderness can be confusing and intimidating. Therefore, in this paper, we present a perspective on health psychology theory that enables organising theories to facilitate 
operationalisation and thereby application and further development. This possibility to organise theories 'on demand' may supersede the need for developing integrative theories. Specifically, we propose that instead of striving to build a Theory of Everything (the ultimate integrative theory that does not exclude potentially important variables), adopting the pragmatic nihilistic stance of a Theory of Nothing may be more beneficial to health psychology progress. In this paper, we explain what this pragmatic nihilistic stance entails, aiming to convey a perspective that can afford a certain flexibility in thinking about and employing psychological theory. Note that we use the terms 'pragmatism' and 'nihilism' in their everyday meanings rather than their quite extreme philosophical meanings: as will become clear, these terms simply concisely capture the first two tenets of the perspective we discuss. Although at first glance, 'pragmatic nihilism' might sound pessimistic about the state of our science, we hope to persuade the reader of the opposite: that accepting both premises (i.e., what we termed 'pragmatism' and 'nihilism') affords scientists a refreshing and empowering flexibility in the development and application of theory without the need for a Theory of Everything.

Theory is used in understanding behaviour, which is one of the aims of health psychology (Ogden, 2012) and a prerequisite for changing behaviour (Bartholomew-Eldredge et al., 2016). Research to achieve this understanding of behaviour focuses on psychological variables that causally predict behaviour. In fact, because overt behaviour results from activation patterns of the motor cortex and activation patterns in the motor cortex are the result of activation patterns elsewhere in the brain (Graziano \& Aflalo, 2007), all overt behaviour is necessarily caused by such psychological variables in all conceivable cases except physical coercion. All environmental (e.g., social or physical) and genetic influences on behaviour eventually operate through (and manifest as) psychological variables (Moore \& Depue, 2016), which, in the context of behaviour change, are called determinants. As a consequence, the literature on behavioural determinants is extensive, and theories aiming to explain behaviour such as the Reasoned Action Approach (RAA; Fishbein \& Ajzen, 2010) and its predecessors (e.g., the TPB; Ajzen, 1991), SDT (Ryan \& Deci, 2000), and the Extended Parallel Process Model (EPPM; Witte, 1992) are popular.

Such theories provide definitions of psychological variables as well as of processes operating on those variables. These variables can be and frequently are distinguished using a variety of dichotomies, such as 'cognitive' versus 'emotional' determinants or 'reflexive' versus 'reflective' determinants. The definitions of these variables establish exactly what is, and what is not, part of the defined variable, and thereby enable operationalisation of the variable. These operationalisations can be measurement instruments that measure the variable, or manipulations that change the variable. ${ }^{1}$ Both types of operationalisations consist of stimuli such as items (e.g., questions), words, or images, which are then presented to and processed by people (for quantitative measurement instruments and qualitative research, a response is also recorded).

\section{Nihilism: dropping the assumption that psychological variables need to 'exist'}

Although each of these stimuli is hypothesised to correspond to mental representations, these representations are not generally assumed to be stored as separate 'units'. People do not have a brain region storing 'beer bottle labels' or 'examples of seventeenth-century Dutch architecture'. In fact, it is even unlikely that a set of neurons can be identified that represents 'beer bottles', or even the concept of 'bottles' or 'buildings'. Of course, stimuli do exhibit regularities, and these allow people to categorise them. Sadness always feels similar to a certain extent; all bottles look similar in a number of respects; and all exercise behaviours resemble each other more than they resemble fruits or beer bottle labels. However, these patterns do not necessarily imply that our minds store this information in a modular fashion. Although this intuitive hypothesis underpinned many early neuroscientific studies, nowadays meaning, concepts, and semantics are generally assumed to be stored in a distributed manner (Behrmann \& Plaut, 2013). In fact, they have been argued to be 
emergent properties: 'beer bottleness' exists as a property of the system of our minds, although no single neuron or cluster of neurons represents this concept.

In this paper, we will work from this premise that cognition (e.g., instrumental attitude and goals) and emotion (such as feelings urging approach or avoidance and experiential attitude), as well as the processes operating on cognition and emotion (such as aspects of self-regulation and vicarious learning) may only exist as emergent properties in a distributed network of neurons. Thus, cognitions and emotions are useful constructs when theorising about behaviour, but cannot be pinpointed physically in people's brains. Global patterns can be identified, such as that parts of the cortex that developed more recently (e.g., the frontal cortex) contain more higher-level functions; and anatomical structures such as the amygdala have been identified that play a role in specific aspects of human psychology such as emotion. However, at a more specific level, making action plans or experiencing anger corresponds one-on-one to activation in a particular brain area. Instead, distributed activation patterns have recurring features that correlate with, for example, behaviour. We label such recurring features that vary over time (i.e., variables) as cognitions and emotions, and these are useful metaphors in understanding and modelling the world. The assumption that the variables hypothesised by theories in fact exist as more than flexibly employable metaphors is not necessary for theories to be useful.

However, dropping the assumption that the hypothesised variables and processes 'exist' removes a more or less 'tangible' foundation that many find reassuring in a field that is already defined by uncertainty, such as science (or specifically, health psychology). In this paper we aim to provide a foundation that provides a similarly secure base from which to apply or further develop health psychology theory, while enabling moving away from reliance on actual existence of the variables and processes included in health psychology theory. Moreover, this foundation aspires to provide means to relate any number of health psychology theories to each other in their representation and application. Thus, by building this foundation from the somewhat nihilistic perspective that the variables hypothesised by our theories do not exist (or at least, that their existence as more than metaphors need not be assumed), we aim to replace the need for a Theory of Everything by a Theory of Nothing that promotes continuous theoretical integration as opposed to discontinuous integration through new, integrative, theories.

\section{Pragmatism: introducing operationalisations as crucial interfaces}

The starting point of this foundation is the concept of spreading activation. Neurons communicate by exciting or inhibiting each other, resulting in spreading activation patterns. For example, observation of a rapidly approaching ball activates and inhibits neurons in the visual cortex, and those neurons activate and inhibit others, until the patterns of spreading activation reach the motor cortex and one attempts to evade or catch the approaching ball. These patterns of spreading activation are also a useful metaphor at higher levels: for example, the Deese-Roediger-McDermott paradigm (Roediger \& McDermott, 1995) exploits the characteristics of spreading activation through a semantic network to create false memories, and the popular concept of free association is an example of spreading activation applied to entire memories.

Imagine a network of characteristics, some almost indistinguishable such as 'goodness' and 'beneficiality', some opposite such as 'harmfulness', and some seemingly unrelated such as 'shame' and 'guiltiness' (Figure 1). Which specific characteristics (i.e., variables) we place in the network is not relevant to this explanation: the core concept is that of a network of interlinked characteristics. These characteristics could be feelings, or aspects of emotions, or estimates of likelihood, or elements of meaning: the important thing is that they are associated. Now, consider how the definition of a variable would manifest in such a network: it would consist of a division of all elements in the network into those that are a part of the defined variable, and those that are not. For example, the well-known social cognitive variable 'attitude' could be defined as pertaining to the interestingness, perceived harmfulness, pleasantness, goodness, and beneficiality of a behaviour, object, or other entity (see 


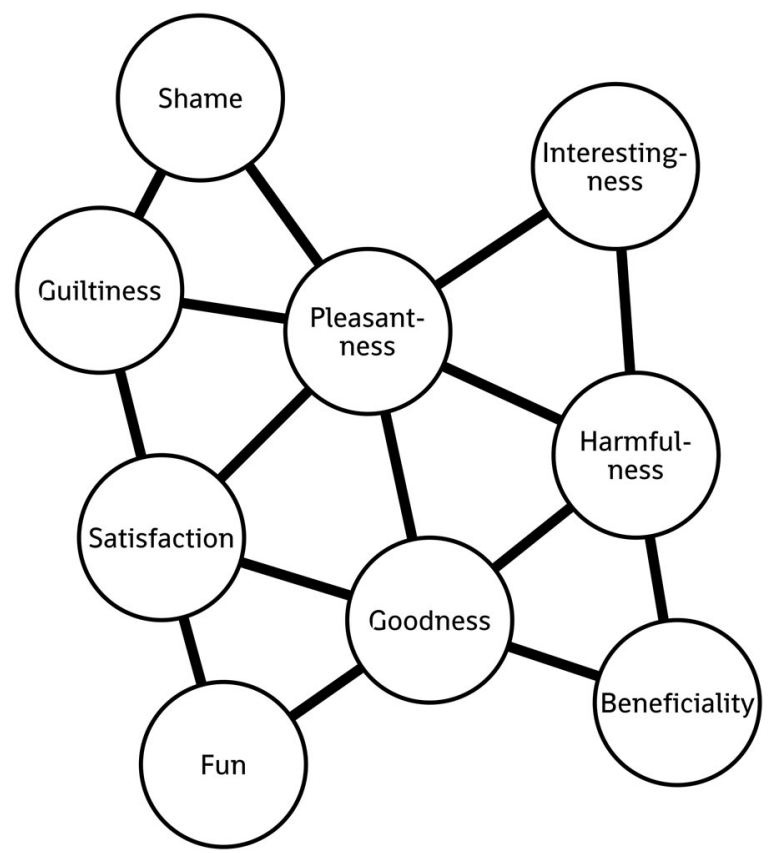

Figure 1. A network of characteristics such as might pertain to a behaviour.

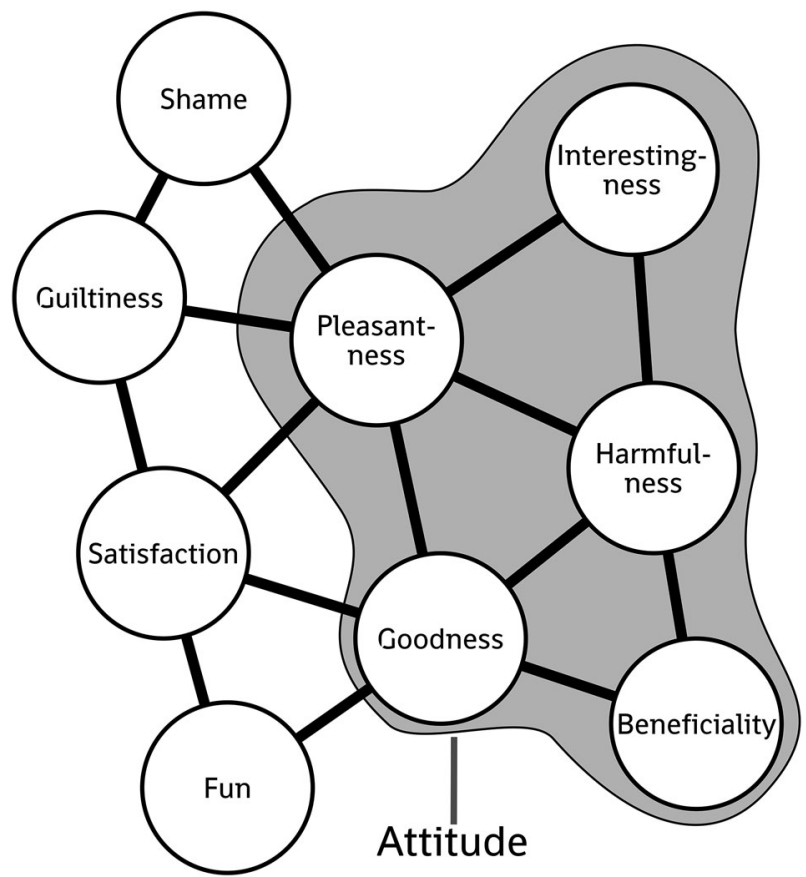

Figure 2. A variable (attitude) expressed as connected characteristics of, for example, a behaviour.

Figure 2; also see Dalege et al., 2016). This definition enables operationalisation of the construct of attitude: for example, the direct measurement of attitude consists of semantic differentials with anchors like 'harmful' versus 'beneficial', 'boring' versus 'interesting', and 'unpleasant' versus 
'pleasant' (Fishbein \& Ajzen, 2010). However, when following the guidelines of Fishbein and Ajzen (2010), attitude would not be assessed with items measuring, for example, whether a behaviour makes one feel 'ashamed' versus 'proud'. For all practical purposes, the operationalisation is the construct of attitude.

In this assumption lies the pragmatism of this approach: we need not assume that attitude exists to formulate guidelines for the measurement of something, and if that measurement can then be used to successfully predict or change behaviour, attitude is apparently a useful variable. At the same time, from adopting this pragmatic nihilistic stance follow some implications for variable definition and operationalisation. For example, if a theory states that a variable contains aspects that are not included in the operationalisation, the validity of that operationalisation is threatened. And, less obvious at first glance: the validity of any operationalisation that assesses cognitions, emotions, or elements of a process that are not included in the definition of the relevant variable or process, is also threatened. Thus, pragmatic nihilism holds that variables certainly exist as their operationalisations, but may not, and need not, exist otherwise. This places a strong burden on the researcher to guard the clarity and scope of, as well as verify and report the validity of their operationalisations (Crutzen \& Peters, 2016). Data about a variable are only as good as its operationalisation, and therefore, any theory should include, in addition to clear definitions, instructions for operationalisation of each variable (a point recently made by Brewer, 2016 as well). The RAA and the EPPM are examples of theories doing an excellent job in this respect. For example, Witte, McKeon, Cameron, and Berkowitz (1995) provide a Risk Behaviour Diagnosis Scale that contains skeleton items to be completed with the target behaviour and health threat at hand, such as '[Recommended response] is effective in preventing [health threat]'. Fishbein and Ajzen (2010) approach this even more thoroughly by providing guidelines for conducting Belief Elicitation: a method of identifying the relevant beliefs that underlie their determinants.

\section{Operationalisations in dimensions}

Inspection of operationalisations of a variety of psychological variables reveals some patterns in how these operationalisations differ. Specifically, a number of dimensions can be distinguished, an important one of which is specificity versus generality. For example, the dual process theory of Strack and Deutsch (2004) states that behaviour is predicted by implicit associations (among other variables), which can be represented in a network similar to that shown in Figures 1 and 2 (see Figure 2 of Strack \& Deutsch, 2004), and measured using, for example, the Implicit Association Test (IAT; Greenwald, Mcghee, \& Schwartz, 1998). In the IAT, participants are presented with words and/or images from carefully compiled sets, where each set is designed to activate a specific mental representation. Applied to alcohol consumption, one can for example use words such as 'Whiskey', 'Wine', and 'Beer', alternatively specifically assess beer-related implicit associations by using words such as 'Budweiser', 'Heineken', and 'Guinness', or even stick to one category of beers by using words such as 'Leffe Tripel', 'Tripel Karmeliet', and 'Chimay Blanc' (for an example, see Houben \& Wiers, 2006). Using words from the broadest category results in generic associations that predict general alcohol consumption to a certain degree. Using words from the narrowest category will predict the associated (narrowly defined) behaviour more strongly (in this case, consumption of Tripel beers), but perform less well in the prediction of the generic behaviour (alcohol consumption), and in the prediction of other, related, although equally narrowly defined, behaviours (e.g., consumption of malt whiskeys), and even worse for less related behaviours (e.g., rope-skipping).

Another example is self-regulation theory, variables from which are operationalised using the SelfRegulation Questionnaire, which features items such as 'I doubt I could change even if I wanted to'. This operationalisation could be made more specific by specifying these items for one specific point on one of the 'operationalisation dimensions', such as timeframe (e.g., 'I doubt I could change within the next year even if I wanted to' or 'I doubt I could change in the next week even if I wanted to'), context (e.g., 'I doubt I could change when I'm around my friends even if I wanted to' or 'I doubt I 
could change when I'm very busy even if I wanted to'), or behaviour (e.g., 'I doubt I could change my exercise behaviour even if I wanted to' or 'I doubt I could change my alcohol consumption even if I wanted to'). Again, more specific operationalisations enable better prediction of behaviour that is consistent with the specification, at the cost of predictive power for other behaviours: participants' answers to 'I doubt I could change my alcohol consumption even if I wanted to' predict their alcohol consumption better than 'I doubt I could change even if I wanted to', but their exercise less well.

The RAA deals with the existence of four of these dimensions explicitly in what was called the TACT principle in its predecessor, the TPB. The TACT principle holds that proper measurement of the TPB constructs requires they be consistent in Target, Action, Context, and Time. For example, successful prediction of whether participants will get a colonoscopy in the next two months requires measuring attitudes towards themselves (Target) getting a colonoscopy (Action) given their situation (Context) in the next two months (Time). This principle, simply called the compatibility principle in the RAA, suggests that people's attitudes towards 'getting a colonoscopy' will predict whether people get a colonoscopy in the next two months less well than the more compatible operationalisation including, for example, the time frame.

It is important to note that any operationalisation entails implicit (or explicit) choices regarding these dimensions. Figure 3 shows an item (i.e., an element of an operationalisation) measuring people's intention to go running. The top-most panel shows five versions of the item, differing on two dimensions (behavioural specificity and time). The bottom-most panel also shows five different versions, now varying on duration and time. In addition to the four dimensions in which psychological variables can be compatible that are emphasised by the RAA, more exist. Which of those dimensions are relevant or sensible to distinguish varies from theory to theory. For example, specificity of target population can also be relevant, as determinants of behaviour can differ between subpopulations. Therefore, studies into the determinants of condom use in the general population may have relatively low usefulness when developing an intervention for migrant transgender sex workers, whereas studies with sex workers in general may still have some usefulness; and studies into determinants of exercise among university students are more useful when developing an intervention for young people in general than when developing an intervention for the general population. Many dimensions other than target population, context, time, and behavioural specificity exist, and we do not mean to imply that any of these are particularly central or important.

\section{Levels of aggregation of determinants}

We do mean to emphasise one additional dimension that transcends all theories: that of level of psychological aggregation. All variables (and in fact, processes) postulated by health psychology theory have a level of aggregation. For example, in the RAA, the determinant intention is predicted by the three lower-level variables attitude, perceived norms, and perceived behavioural control. Attitude, in turn, can be considered to consist of experiential and instrumental attitude; and each of these consists of attitudinal (or: behavioural) beliefs. Figure 4 illustrates this aggregation level hierarchy using the 'spreading activation examples' from earlier: experiential attitude can be considered to consist of a subset of the elements of those that attitude consists of. Intention would contain attitude as whole, including the elements included in the definition of perceived norm and perceived behavioural control. The RAA then, as visualised in such a spreading activation network, would hold that reasoned (or planned) behaviours are predicted by activation patterns that depend primarily on the configuration of networks consisting mainly of those elements that are parts of the definitions of attitude, perceived norm, and perceived behavioural control (which together form intention; see Figure 5).

In addition to visualising how a theory's variables at the different levels of psychological aggregation relate to each other using spreading activation networks, showing these relations in a model can be insightful. Figure 6 shows this for the RAA, but, where Figure 5 visualises the spreading activation 

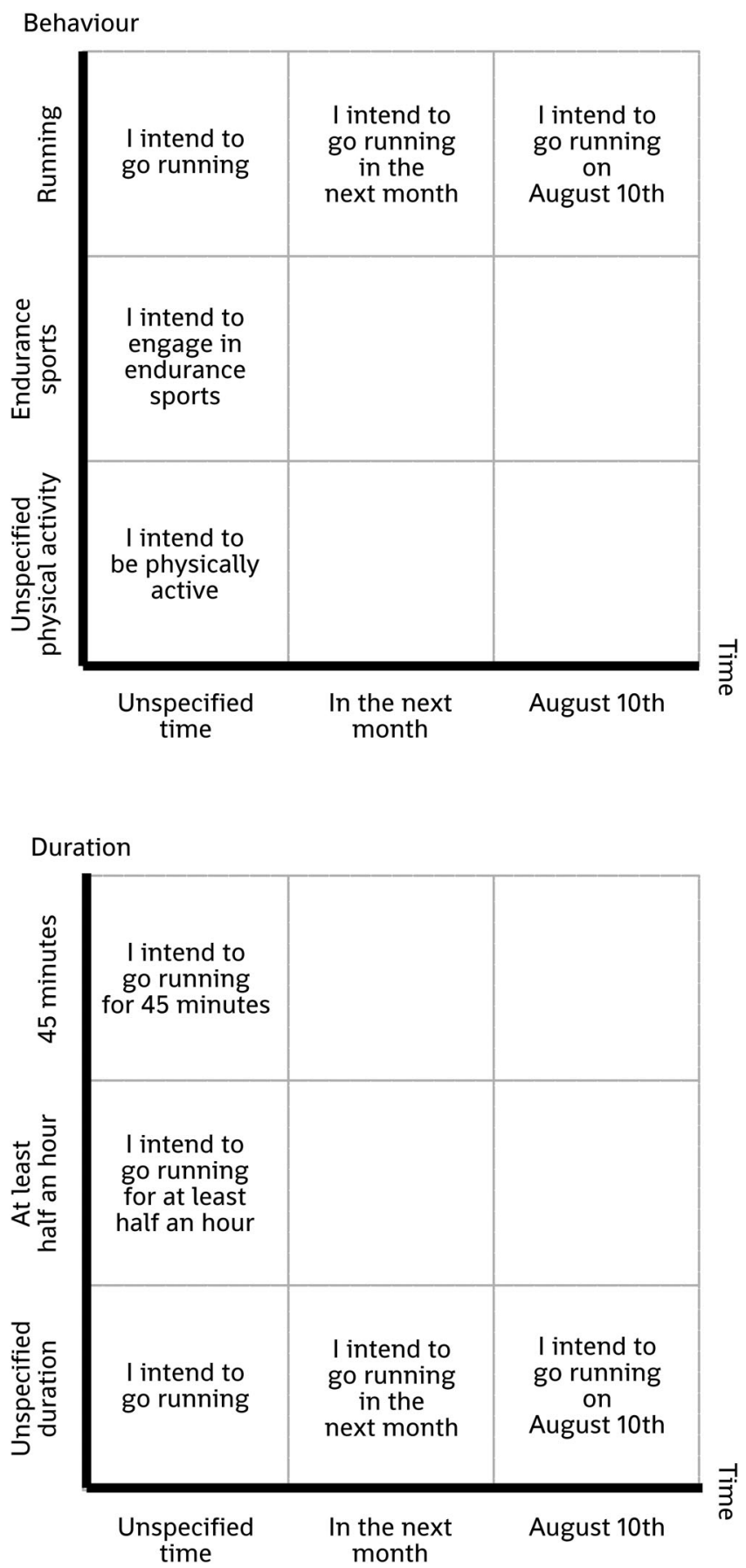

Figure 3. Various operationalisations of an item measuring intention to go running.

metaphor where 'super-variables' consist of 'sub-variables', here super- and sub-variables are shown as independent entities: the determinant most proximal to behaviour is intention, which is predicted by three determinants: attitude, perceived norm, and perceived behavioural control. The RAA postulates that each of these consists of two determinants such as instrumental and experiential attitude for attitude. Each of these again consists of, or is predicted by, determinants that relate to specific 


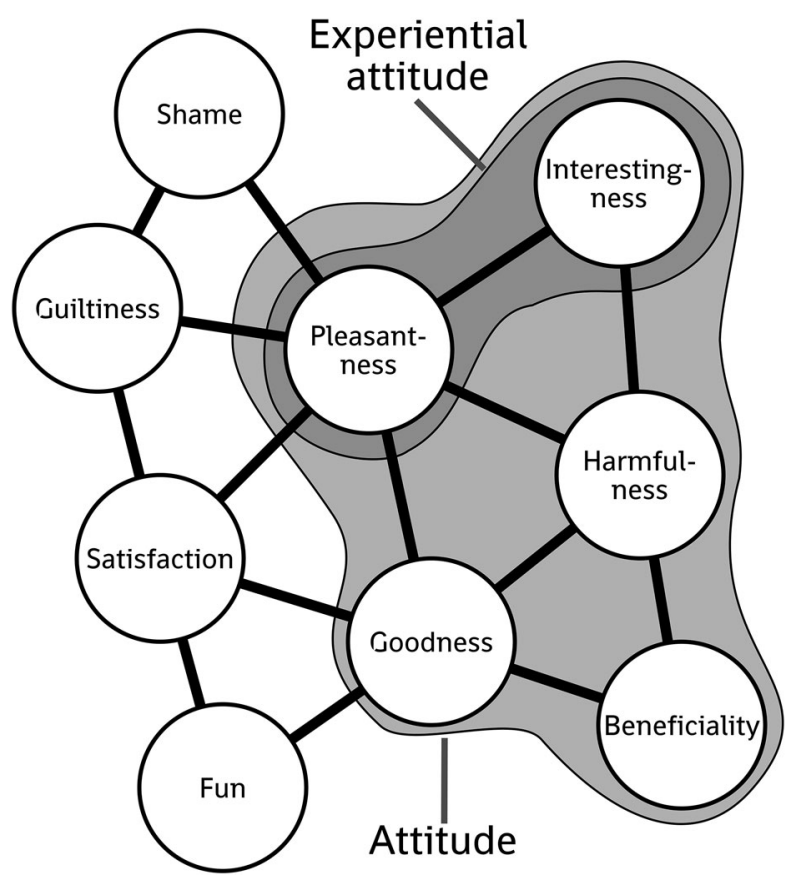

Figure 4. The relative levels of aggregation of attitude and experiential attitude illustrated using the 'spreading activation' metaphor.

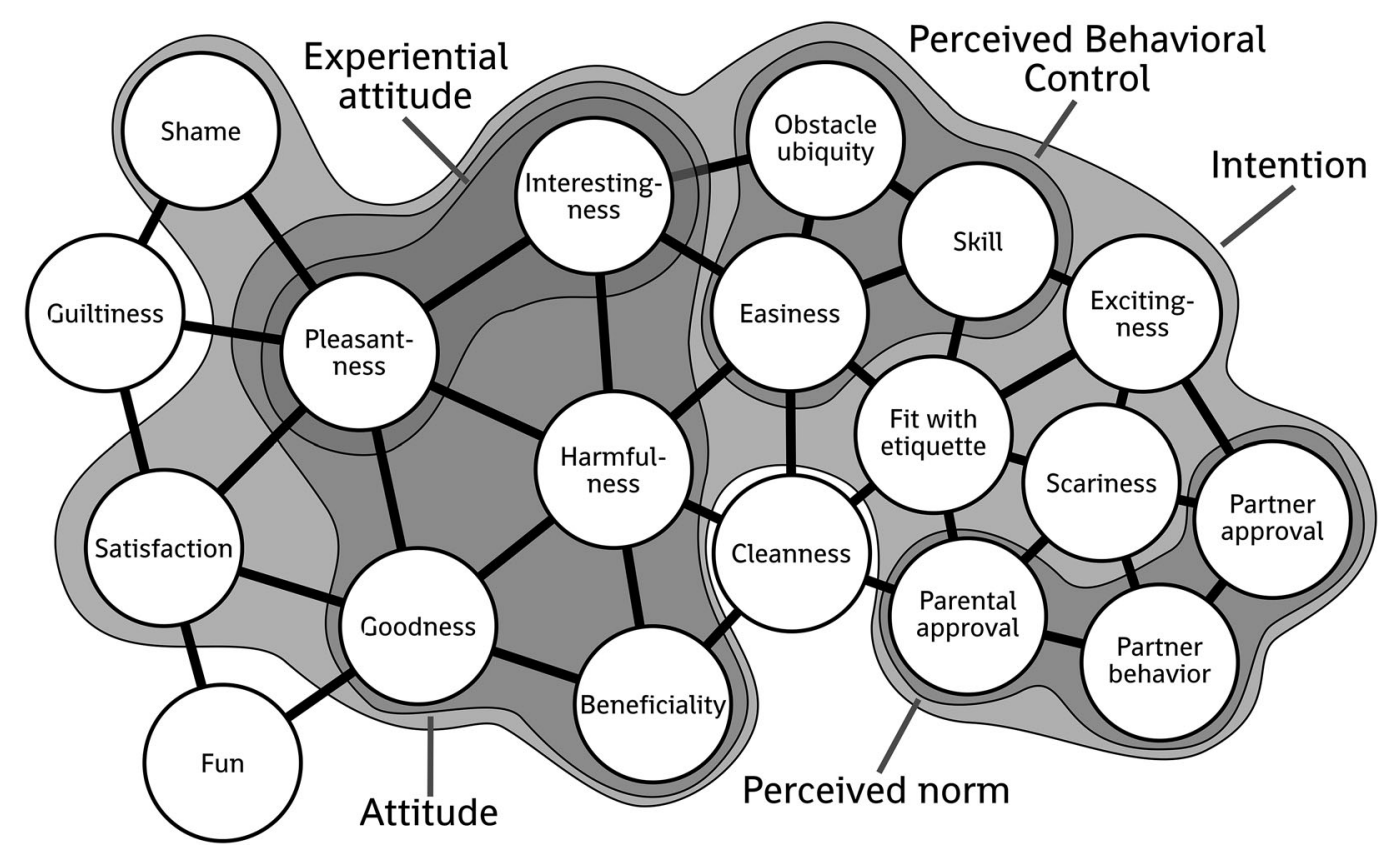

Figure 5. The main RAA variables illustrated using the 'spreading activation' metaphor. 


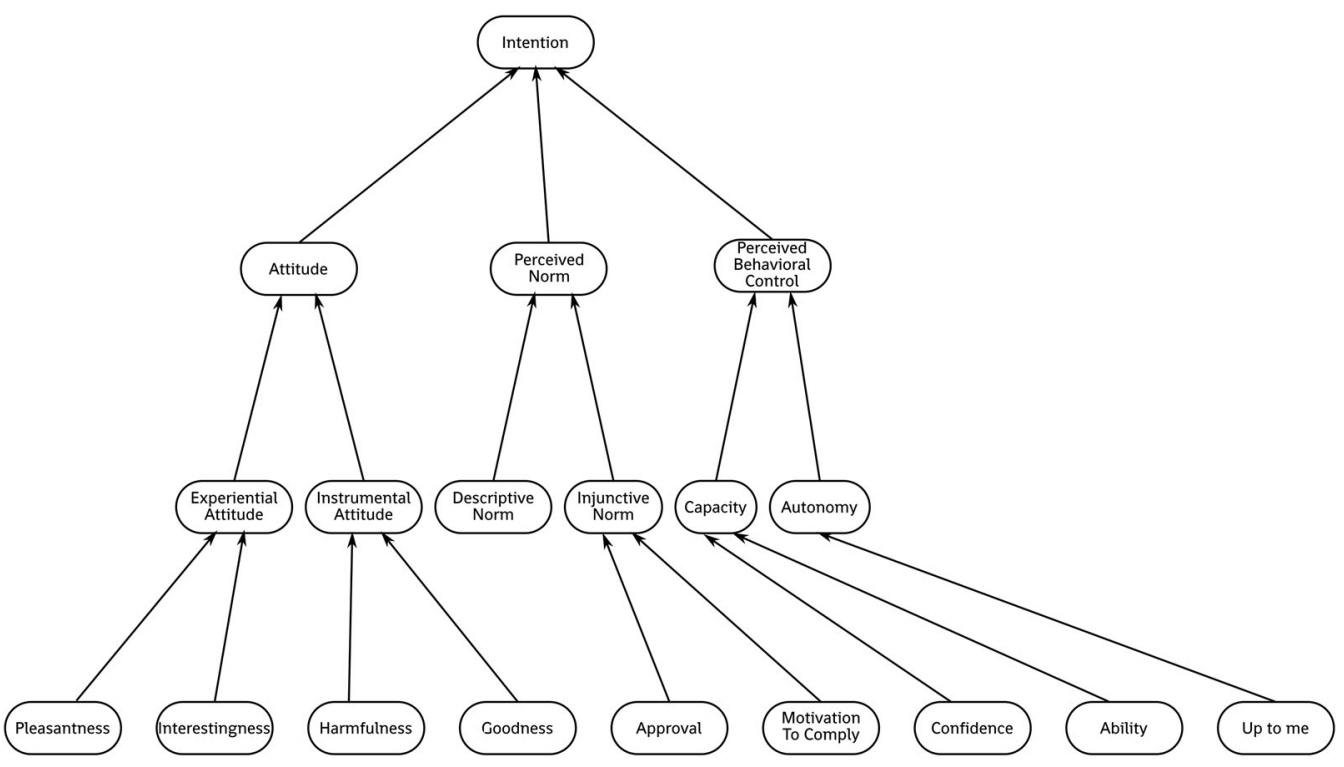

Figure 6. The RAA with its variables as separate entities that relate to each other.

aspects of the relevant behaviour, often called behavioural beliefs. All these RAA variables can pertain to any level of specificity or generality; for example, they can relate to exercising (without specifying e.g., duration, time, context, or nature), or they can relate to running for 45 minutes on Saturday morning after a concert of Viva la Fête.

\section{Operationalisations as slices of the tesseract}

Figure 7 shows the 'running item' from Figure 3, now also varying on the psychological specificity-generality dimension, or level of psychological aggregation (right-hand panels). These four panels together show 20 versions of an item that measures some psychological variable as it relates to running. The precise wording of the item (and thereby, what exactly it measures) changes depending on the position along each of the four dimensions. Recall that there exist many more than four dimensions; those we chose here as illustration are by no means the most important ones. What is important is to acknowledge the existence of these dimensions. The conceptualisation and measurement of any psychological variable corresponds to certain positions on such dimensions, and any item is the consequence of choices as to positions on these dimensions. Any item (any element of an operationalisation) can be more or less specific about behaviour, duration, timeframe, context, etc. A useful analogy is the tesseract: while imagining specificity of behaviour is relatively easy (like imagining a point on a line), adding a second dimension like timeframe makes it a bit more complicated (like imagining a point on a surface, or in a coordinate system), then adding a third dimension like period becomes even more complicated (a point in a three-dimensional space is already hard to represent in two dimensions), and when a fourth dimension is added such as psychological specificity, it becomes almost impossible to imagine (like a tesseract, a four-dimensional 'cube', is almost impossible to imagine, even though the concept of it is relatively easy). Thus, any item in an operationalisation by definition represents a 'slice of the psychological tesseract' (although of course, the slice fixes the item's value on more than four dimensions; in that sense, we use the tesseract as metaphor for the more abstract concept of a hypercube of an unknown number of dimensions).

It is important to note that most theories' operationalisations are at a low level of psychological aggregation (a high level of psychological specificity). This makes sense: because operationalisations 

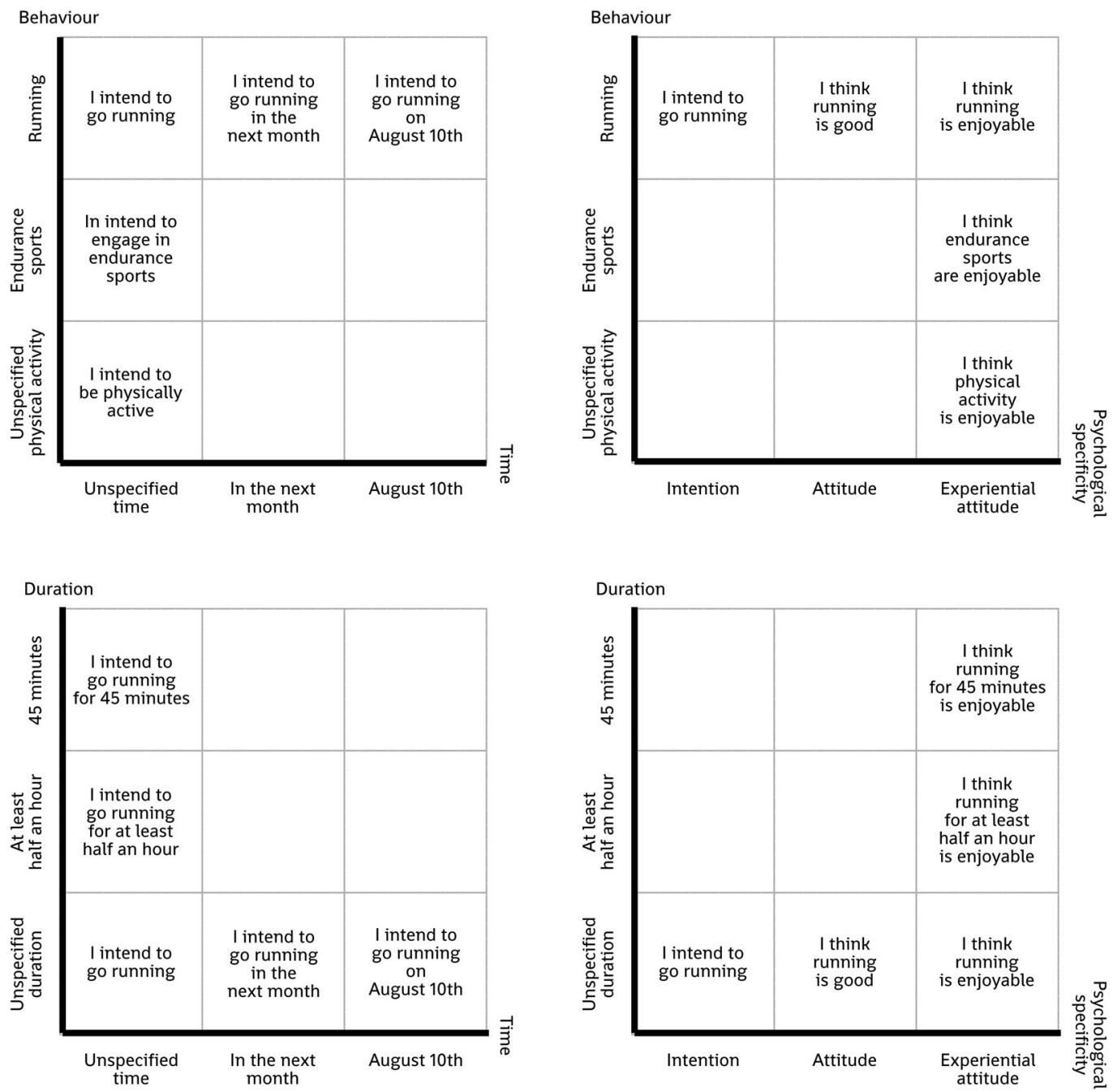

Figure 7. Items pertaining to running, varying on four dimensions of specificity.

are stimuli that people process (and respond to, for operationalisations that measure rather than manipulate a variable), they need to have sufficient specificity to relate to real-world phenomena. How to translate a theory's variables to operationalisations that utilise natural language, images of real-world entities, and knowledge of real-world phenomena should be part of the instructions that accompany a theory's variable definitions. For behaviour change, these operationalisations are even more crucial, as anything targeting a determinant of behaviour must work on this same 'real-world' level of specificity. For example, when applying the RAA to increase intention to exercise, one would not craft messages like 'have a high intention to exercise' (which would directly target intention), but rather something like 'exercise makes you feel good about yourself' (which targets one of the beliefs underlying attitude). Thus, pragmatic nihilism holds that clear prescriptions for operationalisations not only enable measurement (and thereby research), they also enable behaviour change. Conversely, theories that do not provide clear links from their more generic, abstract constructs, through lower-level variables, to a level of sufficient psychological specificity to enable interfacing with tangible aspects of reality, cannot be utilised in behaviour change interventions.

It is also important to note that considering variables as 'predicted by' other variables, as implied in Figure 6, or 'consisting of' other variables, as implied in Figure 5, is almost interchangeable according 
to pragmatic nihilism. Considering psychological variables as possibly non-existent, but certainly useful metaphors, equal to their operationalisation for all practical purposes, means that distinguishing whether variables predict each other or contain each other becomes both hard and less relevant to successfully predicting and changing behaviour. If experiential attitude and instrumental attitude together form attitude, changing either of them should result in a (smaller) change in attitude. Conversely, if attitude changes, depending on which specific elements of attitude change, one or both of experiential and instrumental attitude also change. The aim of pragmatic nihilism is not to disentangle these scenarios of causality or constitution; rather, to provide a foundation for relating theories to each other.

In addition to the RAA, we will show two more examples of such a hierarchy of constructs from generic, more abstract determinants (theoretically often assumed to be more proximal predictors of behaviour), to more specific determinants, and eventually operationalisations. The second example is shown in Figure 8, showing the EPPM. The EPPM proposes that perceived threat and efficacy together determine behaviour, and each of these is again predicted by (or consists of) two determinants. Each of these determinants again can be distinguished in more specific determinants. For example, the operationalisation of self-efficacy, one of the two determinants of efficacy, on the one hand contains elements that relate to one's confidence that one can successfully perform a behaviour, and on the other hand elements that relate to one's perceived ability to perform the behaviour. Although this distinction in intermediate determinants was not specified in the original theory, it can be useful in some contexts, for example, when drawing on the EPPM to change a behaviour where self-efficacy is so important that fine-grained measurement and influence may be key to successful behaviour change.

A final example is shown in Figure 9, where the concepts from SDT are shown in the genericspecific hierarchy. SDT aims to help understand motivation as determinant of behaviour, and it does so by distinguishing types of behaviour regulation. The degree to which behaviour is regulated through each of these types combines to determine the quality of one's motivation, which predicts behaviour according to the SDT. We have derived intermediate determinants from the operationalisations of the regulation types (see e.g., Standage, Duda, \& Ntoumanis, 2006). For example, intrinsic

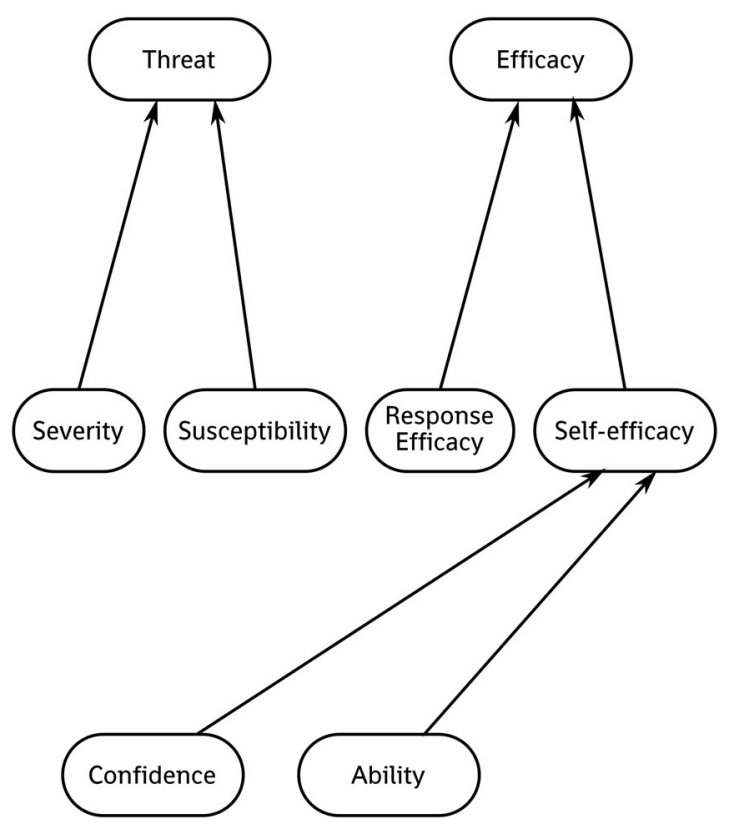

Figure 8. The EPPM shown as interrelating entities. 


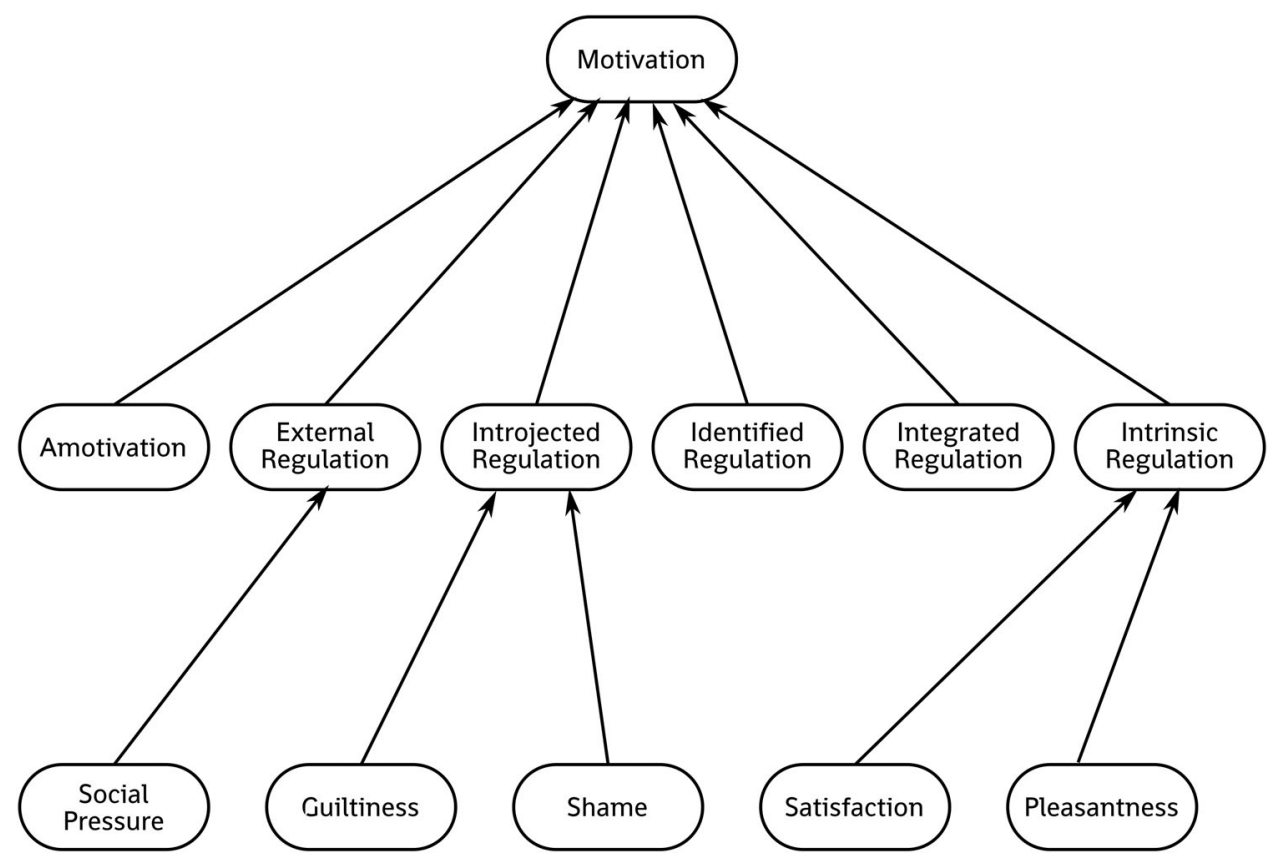

Figure 9. The SDT shown as interrelating entities.

motivation is measured by items such as 'I get pleasure and satisfaction from participating in exercise', which measures both pleasantness and satisfaction, and 'I enjoy my exercise sessions', which measures enjoyment (which could be argued to be similar to pleasantness as well).

\section{Implications of pragmatic nihilism}

This last example shows one of the merits of pragmatic nihilism: its focus on operationalisation makes overlap in theories salient. Pleasantness of a behaviour is part of the definition and operationalisation of both the variable 'intrinsic motivation' from SDT and 'experiential attitude' from RAA. Figure 10 illustrates this using the generic-specific hierarchy, and Figure 11 illustrates this using the spreading activation metaphor. Note that of course, one could argue that any operationalisation of RAA's attitude that does not also measure whether people consider a behaviour satisfying and fun is not a valid operationalisation for the relevant behaviour, assuming both of those determinants ('fun' and 'satisfaction') have predictive value. Proponents of the RAA might argue that belief elicitation procedures would reveal that 'fun' and 'satisfaction' should be included in the attitude measure, and that may be true. Even in that case, though, like any theory's variables, attitude has a definition specifying what is, and what is not, part of the variable. The operationalisations of the variables in SDT clearly imply the existence of intermediate determinants such as 'shame' and 'guiltiness' that predict (or make up) the variable Introjected Regulation (Markland \& Tobin, 2004; Standage et al., 2006). In the case of the RAA, however, shame and guilt have been proposed as aspects of moral norm, a fourth variable that has been proposed as extension to the TPB, RAA's predecessor (Conner, Armitage, \& Armitage, 1998).

Visualising the specificity-generality hierarchy of multiple theories allows showing their overlap, as illustrated in Figures 10 and 11. Combining theories in that manner makes it clear where they overlap and where they do not. The fact that by doing so, pragmatic nihilism bares those aspects of psychology that are not or under-represented in each theory (e.g., aspects such as shame, scariness, and fit with etiquette may contribute to intention without being parts of the definitions of underlying RAA determinants) should not be taken as criticism to the thusly represented theories. Theories deal with 


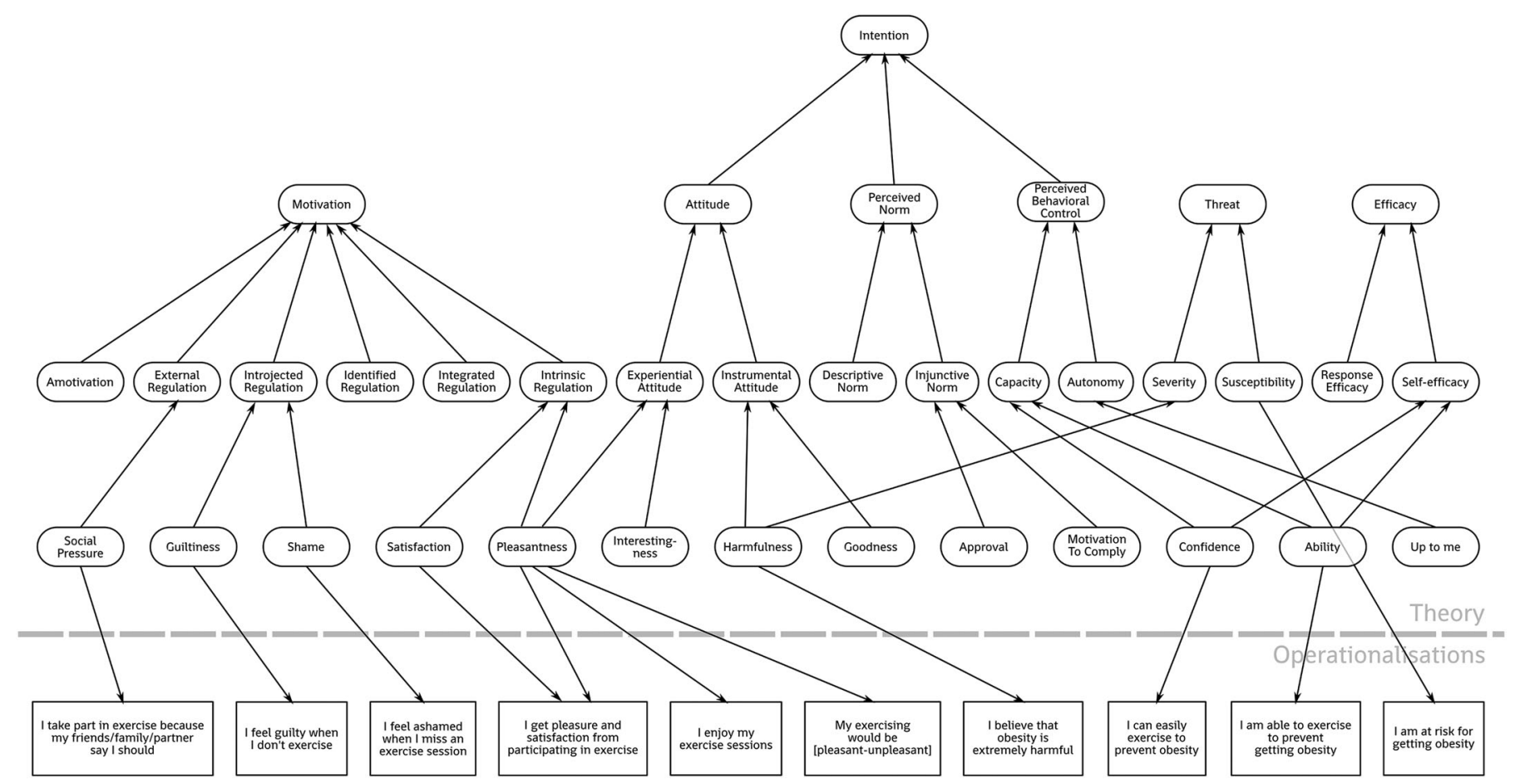

Figure 10. The SDT, RAA, and EPPM and their overlap and operationalisations shown. 


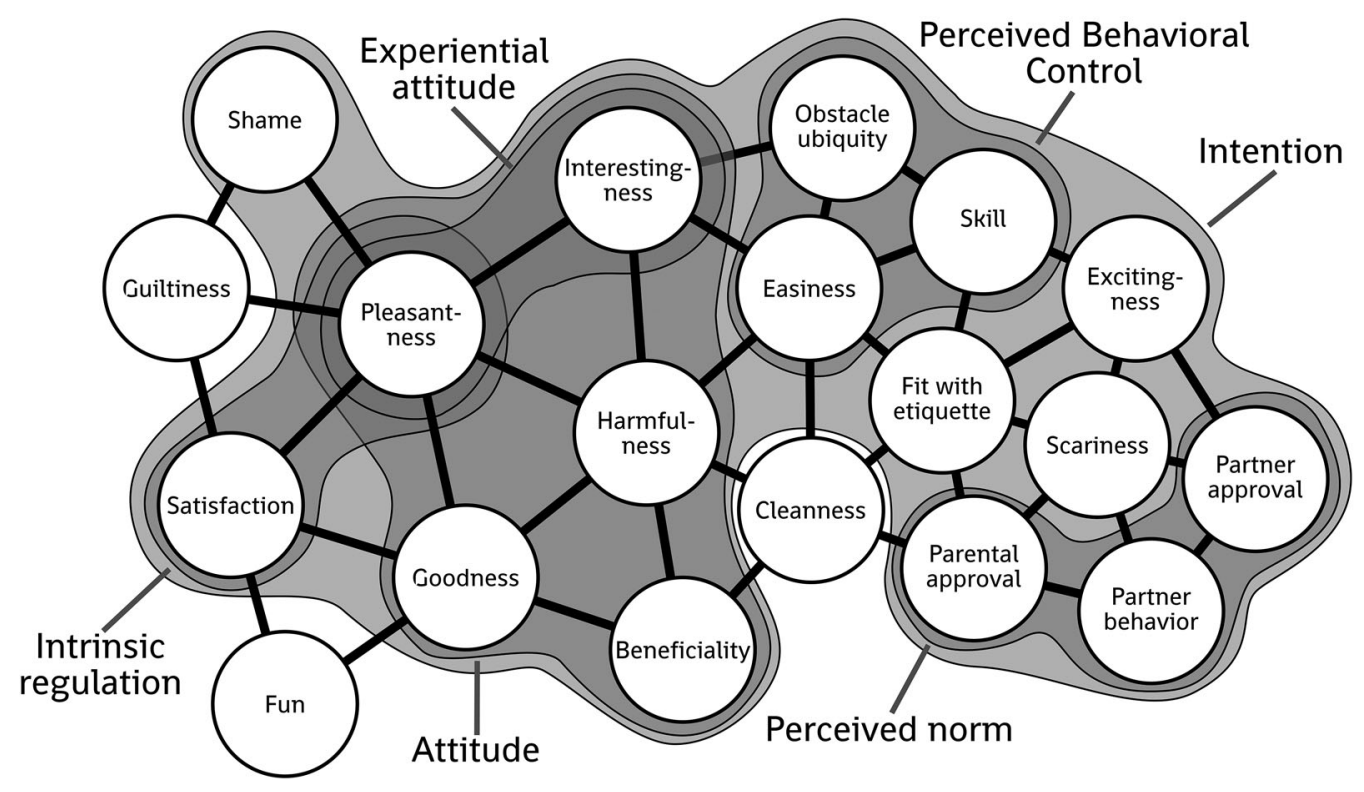

Figure 11. Overlap between the RAA and SDT partially illustrated using the 'spreading activation' metaphor.

bounded aspects of reality. This is not a shortcoming, but a part of the definition of 'a theory' (Kok \& Peters, 2016), or, in other words, this is not a bug, but a feature. This feature merely becomes more salient when combining theories in this manner. That also makes clear why building a Theory of Everything would yield an unwieldy theory: a Theory of Everything would have to contain variables and specifications for operationalisations that can cover the entirety of people's psychology. Because most behaviours can be usefully predicted by a part of people's psychology, it is likely that any psychological Theory of Everything would be accompanied by specification as to when exactly which sections of it are important (which, de facto, means the Theory of Everything is a curated collection of separate theories). In addition, although the anchoring of theories to their operationalisations as proposed by pragmatic nihilism enables combining all theories in one huge overview, at the same time, the awareness of the many dimensions that any operationalisation intersects (i.e., the slice of the tesseract it represents) should warn against such an endeavour.

\section{A Theory of Nothing}

Instead of building a Theory of Everything, we propose a Theory of Nothing. Pragmatic nihilism assigns a crucial role to operationalisations of theories' constructs as their interfaces with reality in terms of both measurement and manipulation. These operationalisations are considered as cross-sections of a multitude of dimensions, such as (but not limited to) psychological specificity (e.g., from behavioural beliefs, through experiential attitude and attitude to intention), behavioural specificity (e.g., from 'running', through 'endurance sports', to 'exercise', to 'physical activity'), and contextual specificity (e.g., from 'Saturday morning after a Vive la Fête concert', to 'in the weekend', to 'during spare time'). The perspective of pragmatic nihilism fosters awareness of the importance of identifying the relevant aspects of people's psychology, as these most specific determinants are eventually what behaviour change interventions can target. Mapping these most specific determinants, for example through a procedure such as 'belief elicitation' as described in the RAA, is necessary to properly operationalise (and thus, measure) variables. Furthermore, since any operationalisation represents a slice of the tesseract, these most specific determinants may differ in any dimension such as target population, context, duration, time, or behaviour changes, either in nature or specificity. 
Recall that pragmatic nihilism emphasises the concepts of dimensions and levels of aggregation without postulating that any specific levels exist or are more important than others. In that sense, the 'levels' and dimensions are merely a useful metaphor, like variables in psychological theories. In fact, although we argue that a certain degree of specificity is required to interface theories with reality and leverage theory to craft effective interventions (or intervention elements) to change behaviour, this level does not represent some end-point; we do not argue that no smaller elements can usefully be distinguished. Psychology is not biology or chemistry: as yet, we are far removed from having any idea as to how the 'atoms of human psychology' would look - if that analogy even holds, and something similar exists at all. The smallest units that are often distinguished in health psychology are on the same level of psychological specificity as the 'beliefs' in attitude research. Variables on this level are still conceptually very rich, referring to many different meanings and dynamics such as causality, probability, and valence (although studies such as that of Dalege et al., 2016 are working towards establishing a finer grained perspective). The lowest possible level will likely break higher-level variables down into fundamental properties such as (aspects of) shapes, colours, and affordances. It can even be argued that although those properties may be convenient to describe our world verbally, that need not be indicative of a central role in the psychological representation of our world. Meaning is represented by activation patterns involving millions of neurons. Mapping all 86 billion (Azevedo et al., 2009) or so neurons may become possible at one point, but the computations required to build and update such a model would cost time, thereby necessarily rendering the model obsolete. This is reminiscent of what is known as the Frame Problem in cognitive science (see e.g., Dennett, 1984): humans' neural configurations change constantly throughout our lives as we are engineered by evolution to learn and adapt, and by the time (e.g., processing time) any procedure mapped any specific configuration, it will already have changed again. Awareness that theories' definitions of psychological variables allocate them at higher levels of psychological aggregation is useful, but these levels are scientific tools to understand and work with human psychology, not objectively existing characteristics of some natural order.

Thus, pragmatic nihilism on the one hand warns against valuing any specific theory too much, by emphasising overlap between theories and each theory's limitations; and on the other hand, emphasises that theories are crucial, because they postulate variables that are useful metaphors when predicting and changing behaviour, enabling this exactly because of those variables' higher levels of aggregation. Without those higher levels of aggregation (without theory), it would be impossible to study behaviour prediction and change over behaviours, because the specific low-level determinants that predict behaviour differ for each slice of the tesseract (i.e., for different behaviours, populations, contexts, times, etc). The knowledge that determinants such as attitude, intrinsic motivation, and response efficacy predict behaviour in general is valuable and conditional upon the use of theory. Without theories that cluster together low-level determinants into higher-level determinants on the basis of their similarity or functional similarity, all behaviours would appear to be predicted by entirely different determinants. Thus, the use of theory is crucial: but which theory one chooses is in some ways secondary. The main concern is identifying all relevant determinants of behaviour in a specific situation. The overlap in definitions between many theories' variables means that various theories can likely perform equally well in the prediction of behaviour in any given situation, as long as the operationalisations of the theories' variables cover the relevant aspects of people's psychology.

From this perspective, the fact that the used measurement instruments are so rarely published in full alongside articles is worrying. If in empirical research, any variable is only as good as its operationalisation, and we argue that it is, it is important that editors, reviewers, readers, and meta-analysists have access to those operationalisations. This underlines the importance of Full Disclosure (Crutzen, Peters, \& Abraham, 2012; Fuller, Pearson, \& Peters, 2013; Peters, Abraham, \& Crutzen, 2012) and of including (and requesting) a 'validation of operationalisations' section in articles' Results sections (Crutzen \& Peters, 2016). This operationalisation-focused perspective also provides some guidance for intervention development: identification of the most effective methods for behaviour change 
requires first identifying the relevant determinants at a sufficiently specific level. A combination of qualitative and quantitative research can help identify the relevant low-level determinants (Peters, 2014), and by consulting health psychology theory, the relevant determinants at higher levels of aggregation can be found. This will enable locating methods of behaviour change (or behaviour change techniques, BCTs) that can change the relevant determinants, as such methods are generally studied at relatively generic levels of aggregation (Kok, 2014). These generic methods can then be translated into more specific applications, as described by the Intervention Mapping protocol (Bartholomew-Eldredge et al., 2016; Kok, 2014; Kok \& Peters, 2016). The importance of operationalisations is also reflected by a recent discussion about, and recommendations concerning, operationalisations of self-efficacy (Beauchamp, 2016; Brewer, 2016; Schwarzer \& McAuley, 2016; de Vries, 2016; Williams \& Rhodes, 2016a, 2016b).

This brings us to some characteristics of theory that we have not yet touched upon. Theories are much more than collections of variable definitions: they also postulate processes that operate on those variables, and conditions under which those processes operate. Many theories predict that variables moderate and mediate each other's effects, and neither such relationships nor processes are explicitly represented in the spreading activation network metaphor or the hierarchical theory representations we presented. That is, when considering variables as separate entities, the indirect effect of experiential attitude through attitude on intention in Figure 6 represents mediation; and in the spreading activation network metaphor, this mediation is also visible in Figure 5, where experiential attitude falls within attitude, which falls within intention. The operation of processes on variables and moderation, which can be considered a process operating upon the association between two variables over time instead of upon the value of a variable, is harder to express in those two metaphors (i.e., spreading activation and the hierarchy of specificity versus generality of psychological variables). It may be that attempts to that effect would stretch these metaphors beyond usability. Like theories derive their usefulness and applicability from the constraints implicit in their nature, pragmatic nihilism is useful when thinking about variables and how they relate to each other as well as when developing interventions, but it may prove a less practical tool when intending to model processes.

\section{Practical recommendations and conclusion}

Nonetheless, we believe that this leaves an abundance of situations in which adopting a pragmatic nihilistic perspective can be beneficial to make sense of both theory and empirical findings. Its focus on operationalisations provides a foundation that can facilitate an eclectic approach to theory. We have compiled a number of recommendations that follow from pragmatic nihilism.

The first set of recommendations apply when identifying the determinants predicting a behaviour as one does when preparing for the development of a behaviour change intervention (Bartholomew-Eldredge et al., 2016; Peters, 2014). In this process, pragmatic nihilism suggests that the most important goal is to identify all relevant aspects of the target population's psychology where it concerns the behaviour at hand. Thus, it would follow that limiting oneself to only measuring the variables included in any one theory would be unwise. Instead, it is recommended to plan for a structured review of qualitative studies, or if resources allow, a qualitative study in the target population. The identified aspects of the target population's psychology (e.g., sub-determinants such as beliefs or elements of a psychological process) can then be compared to the definitions and operationalisational guidelines of psychological theories to identify which combination of theories can most adequately cover these psychological aspects. These theories then seem most appropriate to employ, and the corresponding definitions and operationalisational guidelines can then be used to develop quantitative measurement instruments to study the relative importance of the relevant determinants and their sub-determinants. Pragmatic nihilism predicts that this approach should yield better behavioural prediction than the common practice of taking 
one theory and testing its application in a given situation. Subsequently, this better behavioural prediction enables developing a more effective behaviour change intervention (see the next set of recommendations). Furthermore, pragmatic nihilism holds that if no resources are available at all, researchers can try to locate promising theories and should use their definitions and operationalisational guidelines to manually generate potential sub-determinants at a sufficiently specific level.

The second set of recommendations applies when selecting methods of behaviour change of $\mathrm{BCT}$. Most BCTs can effectively be employed to target one or more specific determinants (see e.g., Kok et al., 2016). A pragmatic nihilistic perspective enables researchers to compile a list of determinants that could be considered to 'contain' the psychological aspects to target according to the different theories (e.g., after having established that pleasantness of a target behaviour seems relevant, a researcher would establish that perceived pleasantness can be considered a part of attitude from an RAA perspective and a part of intrinsic regulation from an SDT perspective). The researcher can then consult the literature to find investigations into methods to manipulate attitude, intrinsic regulation, and other variables that were discovered to encompass pleasantness. From a pragmatic nihilism perspective, it does not matter whether the researcher ends up selecting a method that was designed to change attitude or intrinsic regulation. As long as the method can change the relevant aspect of human psychology, it can contribute to an effective intervention.

Finally, the third set of recommendations applies when evaluating an intervention. If researchers want to explore whether the intervention successfully changed the targeted determinants of behaviour, it is important to make sure the operationalisations of those determinants closely match those sub-determinants that are targeted by the intervention messages: the sub-determinants at a sufficiently high level of specificity (e.g., beliefs). For example, if perceived pleasantness is targeted by one or more behaviour change methods, perceived pleasantness should be measured to establish whether that bit of the intervention was effective. If a variable at a more generic level of psychological specificity is measured, pragmatic nihilism predicts that an effect of the intervention will have watered down, because higher-level psychological variables consist of multiple more specific variables. The emphasis on operationalisations and determinants at low levels of psychological aggregation therefore also facilitates accurate evaluations in line with the actual content of intervention (e.g., intervention messages).

Although the separate elements that together make up pragmatic nihilism are not new (e.g., much of pragmatic nihilism is a more detailed explanation of underlying assumptions in Intervention Mapping; Bartholomew-Eldredge et al., 2016), we believe that this specific configuration that we named pragmatic nihilism can be a useful tool when teaching and researching behaviour change and when developing or evaluating interventions. We hope pragmatic nihilism's implicit encouragement to remain critical, even irreverent, towards all individual theories, can further facilitate such eclectic approaches, inspiring researchers to be more theoretically promiscuous. At the same time, we hope that pragmatic nihilism makes it clear that theory is crucial when predicting and changing behaviour. We hope that pragmatic nihilism helps to move away from behaviour change interventions based on one theoretical perspective, such as the health belief model or the RAA, and towards flexible integration of theories for each specific problem instead of striving towards generic integrative theories. Finally, we believe that a stronger focus on operationalisations, an awareness of the importance of determinants at low levels of psychological aggregation (i.e., high specificity), and the consequences of this awareness for research and intervention development, can help health psychology progress.

\section{Note}

1. Note that manipulations are 'real-world representations' of theoretical constructs and processes just like measurements are. Manipulations differ in that they do not yield data if nothing is measured, but like measurements, they are stimuli crafted or selected on the basis of theoretical guidelines. 


\section{Acknowledgements}

The authors want to thank Herco Fonteijn for his inspiring courses that would become the breeding ground for the ideas in this paper, and Gerjo Kok for valuable insights and comments on an earlier draft of this paper. The authors are also grateful to David Trafimow and two anonymous reviewers for their thoughtful and constructive comments.

\section{Disclosure statement}

No potential conflict of interest was reported by the authors.

\section{References}

Abraham, C. S. (2016). Charting variability to ensure conceptual and design precision: A comment on Ogden (2016). Health Psychology Review, 10(3), 260-264. doi:10.1080/17437199.2016.1190293

Ajzen, I. (1991). The theory of planned behavior. Organizational Behavior and Human Decision Processes, 50(2), $179-211$. Albarracin, D., \& Glasman, L. R. (2016). Multidimensional targeting for tailoring: A comment on Ogden (2016). Health Psychology Review, 7199(June), 1-12. doi:10.1080/17437199.2016.1190294

Azevedo, F. a. C., Carvalho, L. R. B., Grinberg, L. T., Farfel, J. M., Ferretti, R. E. L., Leite, R. E. P., ... Herculano-Houzel, S. (2009). Equal numbers of neuronal and nonneuronal cells make the human brain an isometrically scaled-up primate brain. The Journal of Comparative Neurology, 513(5), 532-541. doi:10.1002/cne.21974

Bartholomew-Eldredge, L. K., Markham, C. M., Ruiter, R. A. C., Fernàndez, M. E., Kok, G., \& Parcel, G. S. (2016). Planning health promotion programs: An Intervention Mapping approach (4th ed.). Hoboken, NJ: Wiley.

Beauchamp, M. R. (2016). Disentangling motivation from self-efficacy: Implications for measurement, theory-development, and intervention. Health Psychology Review, 7199(April), 1-4. doi:10.1080/17437199.2016.1162666

Behrmann, M., \& Plaut, D. C. (2013). Distributed circuits, not circumscribed centers, mediate visual recognition. Trends in Cognitive Sciences, 17(5), 210-219. doi:10.1016/j.tics.2013.03.007

Brewer, N. T. (2016). Building better boxes for theories of health behavior: A comment on Williams and Rhodes (2016). Health Psychology Review, 7199(April), 1-4. doi:10.1080/17437199.2016.1162668

Conner, M., Armitage, C. J., \& Armitage, J. (1998). Extending the theory of planned behavior: A review and avenues for further research. Journal of Applied Social Psychology, 28(15), 1429-1464.

Crutzen, R., \& Peters, G.-J. Y. (2016). Scale quality: Alpha is an inadequate estimate and factor-analytic evidence is needed first of all. Health Psychology Review. doi:10.1080/17437199.2015.1124240

Crutzen, R., Peters, G.-J. Y., \& Abraham, C. (2012). What about trialists sharing other study materials? BMJ, 345, e8352e8352. doi:10.1136/bmj.e8352

Dalege, J., Borsboom, D., van Harreveld, F., van den Berg, H., Conner, M., \& van der Maas, H. L. J. (2016). Toward a formalized account of attitudes: The causal attitude network (CAN) model. Psychological Review, 123(1), 2-22. doi:10.1037/ a0039802

Dennett, D. C. (1984). Cognitive wheels: The frame problem of Al. In C. Hookway (Ed.) Minds, machines, and evolution: Philosophical studies (pp. 129-151). Cambridge: Cambridge University Press.

Fishbein, M., \& Ajzen, I. (2010). Predicting and changing behavior: The reasoned action approach. New York, NY: Psychology Press.

Fuller, T. E., Pearson, M., \& Peters, J. L. (2013). Transparent reporting, the foundation for full disclosure. The European Health Psychologist, 15(3), 67-68. doi:10.2105/ajph.94.3.361

Graziano, M. S. , \& Aflalo, T. N. (2007). Mapping behavioral repertoire onto the cortex. Neuron, 56(2), 239-251. doi:10.1016/ j.neuron.2007.09.013

Greenwald, A. G., Mcghee, D. E., \& Schwartz, J. L. K. (1998). Measuring individual differences in implicit cognition. Journal of Personality and Social Psychology, 74(6), 1464-1480.

Hagger, M. S. (2009). Theoretical integration in health psychology: Unifying ideas and complementary explanations. British Journal of Health Psychology, 14(Pt 2), 189-194. doi:10.1348/135910708X397034

Hagger, M. S., \& Chatzisarantis, N. L. D. (2014). An integrated behavior change model for physical activity. Exercise and Sport Sciences Reviews, 42, 62-69.

Houben, K., \& Wiers, R. W. (2006). Assessing implicit alcohol associations with the implicit association test: Fact or artifact? Addictive Behaviors, 31(8), 1346-1362. doi:10.1016/j.addbeh.2005.10.009

Johnston, M. (2016). A science for all reasons: A comment on Ogden (2016)*. Health Psychology Review, 10(3), 256-259.

Kok, G. (2014). A practical guide to effective behavior change: How to apply theory- and evidence-based behavior change methods in an intervention. European Health Psychologist, 16(5), 156-170.

Kok, G., Gottlieb, N. H., Peters, G.-J. Y., Mullen, P. D., Parcel, G. S., Ruiter, R. A. C. C., ... Bartholomew-Eldredge, L. K. (2016). A taxonomy of behavior change methods: An intervention mapping approach. Health Psychology Review, 10. doi:10. 1080/17437199.2015.1077155 
Kok, G., \& Peters, G.-J. Y. (2016). All models are wrong, but some are useful: A comment on Ogden (2016) on how to celebrate variability of persons, variability of theories, and systematic behaviour change application and research. Health Psychology Review, 10(3), 265-268. doi:10.1080/17437199.2016.1190658

Markland, D., \& Tobin, V. (2004). A modification to the behavioural regulation in exercise questionnaire to include an assessment of amotivation. Journal of Sport and Exercise Psychology, 26, 191-196. Retrieved from http://hdl.handle. net/10242/41476

Michie, S. (2015). Keynote: Building the science of behaviour change. Annual conference of the European Health Psychology Society, Limassol, Cyprus.

Michie, S., van Stralen, M. M., \& West, R. (2011). The behaviour change wheel: A new method for characterising and designing behaviour change interventions. Implementation Science, 6(1), II2. doi:10.1186/1748-5908-6-42

Moore, S. R., \& Depue, R. A. (2016). Neurobehavioral foundation of environmental reactivity. Psychological Bulletin, 142(2), 107-164. doi:10.1037/bul0000028

Ogden, J. (2012). Health psychology: A textbook (5th ed.). New York, NY: McGraw Hill.

Ogden, J. (2016a). Celebrating variability and a call to limit systematisation: The example of the behaviour change technique taxonomy and the behaviour change wheel. Health Psychology Review, 10(3), 245-250. doi:10.1080/17437199. 2016.1190291

Ogden, J. (2016b). Theories, timing and choice of audience. Some key tensions in health psychology and a response to commentaries on Ogden (2016). Health Psychology Review. doi:10.1080/17437199.2016.1190295

Peters, G.-J. Y. (2014). A practical guide to effective behavior change: How to identify what to change in the first place. European Health Psychologist, 16(4), 142-155.

Peters, G.-J. Y., Abraham, C. S., \& Crutzen, R. (2012). Full disclosure: Doing behavioural science necessitates sharing. The European Health Psychologist, 14(4), 77-84.

Roediger, H. L. I., \& McDermott, K. B. (1995). Creating false memories: Remembering words not presented in lists. Journal of Experimental Psychology: Learning, Memory and Cognition, 21(4), 803-814.

Ryan, R. M., \& Deci, E. L. (2000). Self-determination theory and the facilitation of intrinsic motivation, social development, and well-being. The American Psychologist, 55(1), 68-78. doi:10.1037/0003-066X.55.1.68

Schwarzer, R., \& McAuley, E. (2016). The world is confounded: A comment on Williams and Rhodes (2016). Health Psychology Review, 7199(April), 1-3. doi:10.1080/17437199.2016.1162667

Standage, M., Duda, J. L., \& Ntoumanis, N. (2006). Students' motivational processes and their relationship to teacher ratings in school physical education: A self-determination theory approach. Research Quarterly for Exercise and Sport, 77(1), 100-110. doi:10.5641/027013606X13080769704046

Strack, F., \& Deutsch, R. (2004). Reflective and impulsive determinants of social behavior. Personality and Social Psychology Review, 8(3), 220-247.

Teixeira, P. J. (2016). Health behavior change: A field just picking up speed. A comment on Odgen (2016). Health Psychology Review, 7199(June), 1-11. doi:10.1080/17437199.2016.1183507

de Vries, H. (2016). Self-efficacy: Skip the main factor paradigm! A comment on Williams and Rhodes (2016). Health Psychology Review, 7199(April), 1-4. doi:10.1080/17437199.2016.1163234

de Vries, H., Mudde, A., Leijs, I., Charlton, A., Vartiainen, E., Buijs, G., ... Kremers, S. (2003). The European smoking prevention framework approach (EFSA): An example of integral prevention. Health Education Research, 18(5), 611-626. doi:10. 1093/her/cyg031

Williams, D. M., \& Rhodes, R. E. (2016a). Reviving the critical distinction between perceived capability and motivation: A response to commentaries. Health Psychology Review, 7199(April), 1-7. doi:10.1080/17437199.2016.1171729

Williams, D. M., \& Rhodes, R. E. (2016b). The confounded self-efficacy construct: Review, conceptual analysis, and recommendations for future research. Health Psychology Review, 10(2), 113-128. doi:10.1080/17437199.2014.941998

Witte, K. (1992). Putting the fear back into fear appeals: The extended parallel process model. Communication Monographs, 59(4), 329-349. doi:10.1080/03637759209376276

Witte, K., McKeon, J., Cameron, K., \& Berkowitz, J. (1995). The risk behavior diagnosis scale (a health educator's tool). East Lansing, Ml. Retrieved from https://msu.edu/ wittek/rbd.htm 